\title{
Conditioned inhibition and the UCS-CS interval
}

\author{
STEVEN F. MAIER and PETER RAPAPORT \\ University of Colorado, Boulder, Colorado 80302 \\ and \\ KIMBAL L. WHEATLEY \\ Weber State College, Ogden, Utah 84408
}

\begin{abstract}
The role of temporal factors in the development of conditioned inhibition was investigated in a backward conditioning design. Separate groups of rats received tone CSs either 3 or 30 sec following shock presentations. T'he C'Ss predicted the same shock-free interval for both groups. A third group was presented with a random relationship between CS and shock. The CSs were tested by superimposition on a Sidman avoidance baseline and only the group with a 3-sec UCS-CS interval revealed an inhibitory effect of the CS. These results are in accord with predictions made by the Solomon-Corbit model of acquired motivation and by Denny's "relaxation" theory of escape and avoidance.
\end{abstract}

Although the phenomenon of conditioned inhibition has received increasing theoretical (Hearst, Besley, \& Farthing, 1970; Rescorla, 1969) and empirical (Boakes \& Halliday, 1972) attention, little is known about the conditions which produce it and which control its strength. The dominant view is that a negative contingency between the CS (conditioned stimulus) and UCS (unconditioned stimulus) is responsible for the development of inhibition (Hearst et al., 1970; Moscovitch \& LoLordo, 1968; Rescorla, 1969). That is, it is argued that inhibition accrues to a CS whenever the UCS is more probable in the absence of the CS than in the presence of the CS. Thus the predictive value of the CS is stressed and it is argued that the prediction of UCS absence is responsible for the development of conditioned inhibition. As an example, the CS in a backward conditioning design is said to become inhibitory (Siegal \& Domjan, 1971) because it predicts the absence of the UCS for a period of time equal to the intertrial interval (Moscovitch \& LoLordo, 1968).

A number of experiments support such a view. Rescorla (1969) varied the degree of negative contingency between a CS and a UCS and found greater inhibition with greater degrees of negative contingency. Moscovitch and LoLordo (1968) employed three groups of dogs in a backward conditioning design. For one group, each CS followed termination of the shock UCS by $1.0 \mathrm{sec}$ and

This research was supported by Grant MH26827-01 to the first author from the National Institute of Mental Health. Requests for reprints should be sent to Steven F Maier, Department of Psychology, University of Colorado, Boulder, Colorado 80302. was itself followed by $2.0,2.5$, or $3.0 \mathrm{~min}$ until the next shock UCS. A second group received CSs $15.0 \mathrm{sec}$ following UCS termination, and the CSs were again followed by $2.0,2.5$, or $3.0 \mathrm{~min}$ until the next UCS. The final group received CSs $1.0 \mathrm{sec}$ following the UCS, but the CS was followed by a randomly varying UCS free interval averaging $2.5 \mathrm{~min}$. The first two groups showed strong and not reliably different amounts of conditioned inhibition to the CS, the third group showed no conditioned inhibition. From these data, Moscovitch and LoLordo concluded that the development of inhibition in backward conditioning was not influenced by the backward temporal relationship between the CS and the preceding UCS (the UCS-CS interval) but rather was determined by the forward relationship between the CS and the subsequent time period free from the UCS. That is, they concluded that the forward prediction of safety by the CS, the negative contingency, determined the development of inhibition to the CS.

However, there are a number of reasons to suppose that temporal as well as contingency factors should be important in the development of inhibitory conditioning. First, excitatory conditioning is influenced by temporal (Gormezano \& Moore, 1969) as well as by contingency factors (Gamzu \& Williams, 1971, 1973), and some symmetry between excitatory and inhibitory conditioning might be expected. The CS-UCS interval certainly influences excitatory conditioning (Gormezano \& Moore, 1969), and so the UCS-CS interval might be expected to affect inhibitory conditioning, despite the negative evidence presented by Moscovitch and LoLordo.

Second, Denny and his colleagues (Denny, 1971; Weisman, Denny, Platt, \& Zerbolio, 1966; Zerbolio, 
1968) have proposed a "relaxation" theory to account for the acquisition of escape and avoidance behavior which postulates two time-dependent processes, "relief" and "relaxation," which occur following an aversive UCS. Relaxation is said to begin 25 to $40 \mathrm{sec}$, and to peak about $150 \mathrm{sec}$, following shock termination in rats. Relief begins $5 \mathrm{sec}$ after shock removal and ends 10 to $15 \mathrm{sec}$ later. Further, Denny argues that both relief and relaxation are conditionable and, as discussed by Denny, bear a strong resemblance to the conditioned inhibition of fear. Because the occurrence of both relaxation and relief are said to follow a post-UCS time course, Denny's position would argue for the importance of temporal factors in the establishment of conditioned inhibition.

Denny and his co-workers have reported a number of experiments in support of the proposed time courses of relaxation and relief. For example, in order to identify the time course of relief, rats were trained to escape and avoid shock by jumping a hurdle from a black to a white compartment, or conversely (reported in Denny, 1971). On each of the 16 trials, the rat was allowed to remain in the safe compartment for $15 \mathrm{sec}$ following the hurdle response. For different groups of rats, a 5 -sec buzzer began 0,5 , or $10 \mathrm{sec}$ following the beginning of the safe period. The acquisition trials followed a sequence in which two consecutive escape-only trials alternated with two successive avoidance-only (no shock presented) trials, and the buzzer was presented following only the escape trials and so always followed shock. The purpose of using this design was to make the buzzer nonpredictive with regard to shock on the following trial. The conditioned properties of the buzzer were later tested by introducing the buzzer in the shock compartment during escape/avoidance extinction. Conditioned relief was reflected by the facilitation of extinction of the escape/avoidance response. The buzzer produced no facilitation when it began $0 \mathrm{sec}$ following shock, but did produce facilitation of extinction in the groups for which it began 5 or $10 \mathrm{sec}$ following shock termination during conditioning. When the postshock safe compartment confinement interval was increased enough to accommodate CSs beginning at 15 and $20 \mathrm{sec}$ after shock, no facilitation was found. From this data, Denny concluded that relief begins $5 \mathrm{sec}$ after shock termination and ends 10 or $15 \mathrm{sec}$ later.

Finally, a model of acquired motivation recently offered by Solomon and Corbit (1974) strongly suggests that temporal effects in conditioned inhibition should exist. They argue that any strong emotional stimulus directly elicits a primary affective reaction called State A. The onset of State A is said to induce an opponent reaction, called State B, which is in some sense the affeclive opposite of State A. Further, State B is said to be sluggish in that its onset and offset are slow. The organism's subjective state is determined by the arithmetic difference between $\mathrm{A}$ and $\mathrm{B}$. When a stimulus is terminated, the $A$ reaction disappears rapidly, but $B$ remains and dissipates slowly. Thus the net reaction will be for the organism's state to go beyond baseline to a "net B reaction" when the stimulus is terminated, and the $B$ reaction would then gradually diminish, leaving the organism at baseline.

Solomon and Corbit maintain that $\mathrm{A}$ and $\mathrm{B}$ states are conditionable. Since the B state which follows the termination of a stimulus is at a maximum shortly after the termination of the stimulus and then dissipates, the model suggests differing degrees of conditioning to stimuli that occur at different times following an UCS. If the UCS were electric shock, the model would expect greater conditioned inhibition of fear to develop to stimuli that follow the shock by a brief time interval than to those following at a longer time interval, even if the forward prediction of shock absence is held constant. This is because the B state should be greatest shortly after shock termination. This was not found by Moscovitch and LoLordo. Because of the importance of these results, we repeated their experiments with different parameters and a different species as subjects.

Our experiment used rats as subjects. Recall that Moscovitch and LoLordo compared backward CSs with 1- and 15-sec UCS-CS intervals. Denny's experiment, described above, suggests that these two postshock time intervals should not be optimal for revealing differences, since relief is present at both. Thus we compared UCS-CS intervals of 3 and $30 \mathrm{sec}$. We used the same procedure as did Moscovitch and LoLordo for measuring conditioned inhibition. The rats were first trained to avold shock in a shuttlebox on a Sidman avoidance schedule. After avoidance rates stabilized, conditioning was conducted and the CS was tested by being presented while the rat was responding on the Sidman schedule. Conditioned inhibition is revealed by a reduction in the avoidance response rate.

\section{METHOD}

\section{Subjects}

The subjects were 21 white male albino rat', obtained from Simonsen Farms and 90 to 120 days old at the start of the experiment. The rats were individually housed and maintaned on a dark-light cycle.

\footnotetext{
Apparatus

Two standard two-wat shuttleboxes were used They were $467 \mathrm{~cm}$ long, $204 \mathrm{~cm}$ wide, and $19.7 \mathrm{~cm} \mathrm{hign.} \mathrm{The} \mathrm{center} \mathrm{of}$ the shuttlebox contaned a metal divider with a rounded
} 
open archway, $7.8 \mathrm{~cm} \mathrm{high} \mathrm{and} 5.8 \mathrm{~cm}$ wide, cut out of it. Thus, to go from one side of the shuttlebox to the other, the rat was required to run through a hole. The background noise was $73 \mathrm{~dB}$ SPL, and the $1,000-\mathrm{Hz}$ tone $\mathrm{CS}$ added $7 \mathrm{~dB}$ to the background noise. Scrambled shocks were delivered from a Grason-Stadler Model 700 shock source.

\section{Procedure}

All rats first received 20 days of Sidman avoidance trainıng in the shuttlebox. Brief $1.0-\mathrm{mA}$ shocks occurred every $2 \mathrm{sec}$ if no response occurred, and a response postponed shock for $12.5 \mathrm{sec}$. Thus, the shock-shock interval was $2 \mathrm{sec}$ and the response-shock interval was $12.5 \mathrm{sec}$. The rats were then divided into three groups matched on the basis of Sidman avoidance response rate. All groups received four sessions of conditioning while restricted to one side of the shuttlebox, the side being alternated from day to day. Conditionıng sessions were separated by Sidman avoidance training baseline sessions. During conditioning, all groups received 5-sec 1.0-mA shocks and $10-\mathrm{sec}$ tones. One group (Group 3) received a tone $3 \mathrm{sec}$ following each shock, while another group (Group 30 ) received a tone $30 \mathrm{sec}$ following each shock. For both groups, the next shock followed tone termination by a 2-, 3-, or 4-min interval. Twenty such UCS-CS sequences were given each session. A random control group (Group C) received shocks of the same intershock interval as did Group $30(2.5,3.5$, or $4.5 \mathrm{~min})$ and tones on a random-interval 3.5 -min schedule.

All groups received three conditioned inhibition test sessions following the last day of conditioning. Six test trials were presented during each session. On a test trial, the tone was presented for $10 \mathrm{sec}$ while the subjects were Sidman avoidance responding in the shuttlebox, and responses were recorded for the $30 \mathrm{sec}$ before, the $10 \mathrm{sec}$ during, and the $30 \mathrm{sec}$ following each tone. Shocks were not allowed to occur during the 70 -sec trial. Conditioned inhibition is revealed in such a procedure by a reduction in response rate to the CS. One test trial a day was a "dummy" trial with no tone presented, in order to assess the possibiluty that responding changed across the 70 -sec trials because shocks did not occur.

\section{RESULTS AND DISCUSSION}

The results can be seen in Figure 1, which shows each group's responding for 10 -sec blocks across the $70-\mathrm{sec}$ trials, computed as a ratio of the rate of responding occurring during the $30-\mathrm{sec}$ pre-CS period. It should be noted that group differences in baseline response rate did not approach significance, and thus response rate ratios are appropriate. Group C showed a small, but reliable, suppression of responding both during and after the CS (both Wilcoxon $T=0, p<.02$ ). Group 30 did not reliably reduce responding during the $C S$, but reliable response reduction following the $\mathrm{CS}$ was observed $(\mathrm{T}=0, \mathrm{p}<.02)$. The responding of Group 30 and Group C did not differ reliably either during or after the CS. Group 3 showed large suppression to the CS $(\mathrm{T}=0, \mathrm{p}<.02)$ to $39 \%$ of their pre-CS level of responding. This was a larger response reduction than occurred in either Group $30(\mathrm{U}=$ $7.5, \mathrm{p}<.02)$ or Group C $(U=6, p<.02)$. In addition, responding remained strongly suppressed in Group 3 in the $30-\mathrm{sec}$ period following the CS $(\mathrm{T}=0, \mathrm{p}<.02)$. Finally, the dummy trials revealed

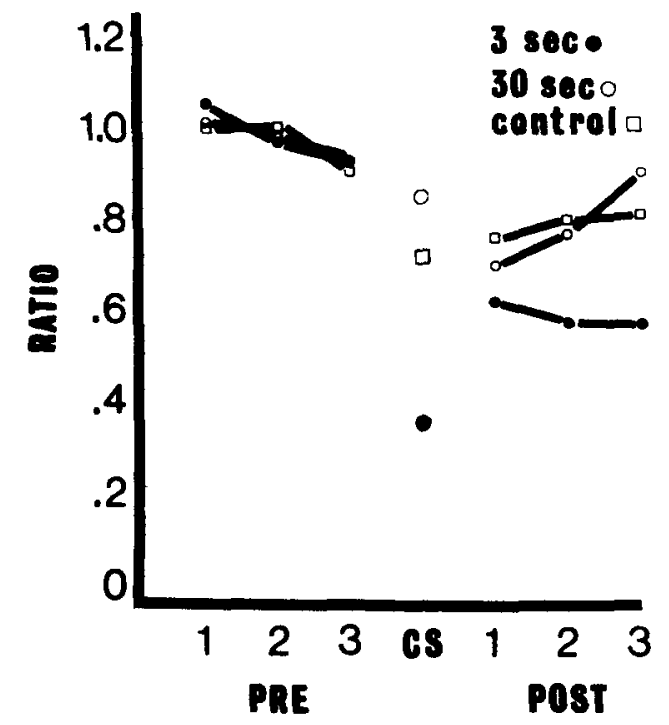

Figure 1. Mean ratio of responses in 10-sec blocks before, during, and after the $\mathrm{CS}$ to the responses during the $30 \mathrm{sec}$ before the $\mathrm{CS}$.

only a small $9 \%$ decrease in responding across the $70-\mathrm{sec}$ trial. Thus the effects here observed are due to the stimulus presentation.

The level of responding to the $\mathrm{CS}$ in Group $\mathrm{C}$ is the baseline against which inhibition can be assessed. Thus, the results provided evidence of strong conditioned inhibition when the UCS-CS interval was $3 \mathrm{sec}$, but no evidence for conditioned inhibition when the UCS-CS interval was $30 \mathrm{sec}$. Temporal factors do, therefore, exert an influence in the development of conditioned inhibition. This does not mean that contingency is unimportant, only that temporal factors also play a role. Thus, a complete theory of conditioned inhibition cannot focus on only the informational aspects of CSs, but must also consider the precise temporal arrangement of UCS and CS. The complete absence of conditioned inhibition in Group 30 may simply reflect insensitivity in our measurement technique for inhibition. Other investigators (Hammond, 1966; Rescorla, 1969; Weisman \& Litner, 1969) have obtained evidence for inhibitory conditioning under circumstances in which the CS did not always closely follow the UCS. Unfortunately, none of these experiments employed a backward conditioning design in which the CS followed the UCS by a fixed temporal interval, and so direct comparisons cannot be made. It thus seems likely that both the negative contingency between CS and UCS and the contiguity of the CS with some post-UCS process determine conditioned inhibition.

The present results differ from those of Moscovitch and LoLordo, who compared UCS-CS intervals of 1 and $15 \mathrm{sec}$ in dogs. In this regard, it can be noted that a dog's heart rate goes below 
baseline following the termination of a shock and often does not return to the baseline for 20 to $30 \mathrm{sec}$ (Church, LoLordo, Overmier, Solomon, \& Turner, 1966). This heart rate reduction is sometimes as large at $15 \mathrm{sec}$ after shock termination as it is $1 \mathrm{sec}$ after shock termination (Church et al. 1966). If the dog's heart rate reduction can be taken as an index of the post-UCS process of relief or B state, Moscovitch and LoLordo may have been sampling time points for which such a process was equally strong. This suggested our use of a 30-sec UCS-CS interval, although species and other procedural differences could also be responsible for the discrepancy in outcome.

Our results provide some support for both the Solomon-Corbit model and Denny's relaxation theory. The prediction that a CS close to shock will become more inhibitory than a CS further removed from shock when both predict equal safe intervals is counterintuitive, yet is strongly supported. We know of no other position which readily makes such a prediction. However, a model of conditioning proposed by Rescorla and Wagner (1972; Wagner, 1971) could make such a prediction if it were argued that contextual stimuli were more excitatory $3 \mathrm{sec}$ after shock than they were $30 \mathrm{sec}$ after shock. This is because the model asserts that the amount of inhibitory conditioning accruing to a CS as a result of its nonreinforced occurrence is directly determined by the amount of excitation conditioned to stimuli present contemporaneously with that CS. We see no compelling reason to assume that contextual stimuli have greater conditioned excitation $3 \mathrm{sec}$ after shock than $30 \mathrm{sec}$ after shock, but such a possibility remains.

Perhaps it could be argued that the prediction of relative safety is greater in Group 3 than in Group 30 because of the slightly higher shock density in Group 3 that was required by the experimental design. Shocks occurred, on the average, every $198 \mathrm{sec}$ in Group 3 and every $225 \mathrm{sec}$ in Group 30. Relative safety time can be obtained by dividing the 180 -sec shock free time predicted by the CS in both groups by the total time between shocks for the two groups (198 and $225 \mathrm{sec})$. It is unlikely that such a difference in the prediction of relative safety time could account for the obtained difference in inhibition since this difference is very small. The CS was followed by $98 \%$ of the intershock interval in Group 3 and by $91 \%$ of the intershock interval in Group 30. There does seem to be a post-UCS process which is conditionable, leads to inhibition, and dissipates with time. This is exactly what is maintained by the Solomon-Corbit model of acquired motivation and by Denny', relaxation theory. However, our findings should be considered as only weak support for these positions in the absence of independent measurement of the time course of such processes following the use of the parameters employed in this study.

\section{REFERENCES}

Boakes, R. A., \& Hailiday, M. S. (Fds.), Inhibution and learming. London Academic Press, 1972.

Chitro h. R. M.. lolordo, V. M.. Overmier, J. B.. Soiomon. R. L., \& TURner, L. H. Cardiac responses to shock in curarized dogs. Journal of Compuratwe and Physiological Psychology. $1966,62.1-7$.

DENNY. M. R. Relaxation theory and experiments. In F. R. Brush (Ed.). Aurrsice conditoning and l'arning. New York: Academic Press, 1971

Gamzu. F.. \& Willams, D R. Classical conditoning of a complex skeletal response. Sctencr, 1971. 171, 923-925.

Gamzu, E., \& Williams, D. R. Associative factors underlying the pigeons key pecking in autoshaping procedures. Joumal of the Experimental Analysis of Behavior, 1973, 19. 225-232.

Gormezano, I.. \& Moore, J. W. Classical conditioning. In M. H. Marx (Ed.), Learning: Processes. London: Macmillan, 1969.

HAMmOND, L. J. Increased responding to CS- in differential CER. Psuchonomic Science. 1966. 5, 337.338.

Hearst, E., Bescey. S., \& Farthing, G. W. Inhibition and the stimulus control of behavior. Journal of the Experimental Analysis of Behavior. 1970. 14. 373.409.

Moscovitch, A., \& Lolordo, V. M. Role of safety in the Pavlovian hackuard fear conditioning procedure. Joumal of Comparanwe' and Phystological Psychology, 1968, 66, 673.678.

Rescorla, R. A. Conditioned inhibition of fear resulting from negative CS-UCS contingencies. Joumal of Comparative and Physologicul Psichologv. 1969.67. 504-510.

RfsCORIA, R A Pavlonian conditioned inhibition. Psichological Bull/lll, 1969, 72, 77.94

Rfscorl.a. R A. d Wagner, A R. A thenty of Pavlovian conditioning. Variations in the ettectiveness of reinforcement and nonreinforcement. In A. H. Black and W. F. Prokasy (Eds), Classical conditioning II: Current theory and research. Neu York: Appleton-Century-Crotts. 1972.

SifgFl. S, \& DOMJAN, M. Backward conditioning as an inhibitory procedure Learming and Motivation, 1971, 2, 1-12.

Solomon. R. L.. \& CORHit, J. D. An opponent process theory of motwatuon. I Temporal dynamics of aftect. Psichological Reve'vi. 1974, 81, 119-145.

Wagner, A. R. Elementary associations. In H. H. Kendler and J. T, Spence (Eds.), Essays in neobehanorism: A memorial volume to Kenneth W. Spence. New York: Appleton-CenturyCrofts, $197 \mathrm{i}$.

Weisman, R. G.. Denny, M. R., Platt, S. A., \& Zerbolio, D. J. Facilitation of extinction by a stimulus associated with long nonshock confinement periods. Journal of Comparative and Physological Psychology. 1966, 62, 26-30.

Weisman, R. G.. \& Litner, J. S. The course of Pavlovian excitation and inhibition of fear in rats. Joumal of Comparative and Phusulegical Prichology. 1969. 69. 667-672.

ZFRBOLIO. D, J. Ficape and approach responses in avoidance learning. Canadian Journal of Psychology, 1968, 22, 60-71.

(Recerved tor publication July 16, 19:5. revisun accepted December 5, 1975 ) 